\title{
Causes and Deaths of Peacocks in the Southern Expressway from Pinnanduwa to Godagama
}

\author{
I. Ariff ${ }^{1 *}$, S. Mohamed ${ }^{2}$ \\ ${ }^{1}$ Department of Geography, University of Peradeniya, Sri Lanka \\ ${ }^{2}$ Faculty of Graduate Studies, University of Colombo, Sri Lanka \\ *isthikar.irf@gmail.com
}

\begin{abstract}
Peacock (Pavo cristatus) is one of the largest and attractive birds in Sri Lanka. Indian peacocks are native to South Asia as well as to Sri Lanka. Low land dry grass areas are their range in Sri Lanka. During the construction of the southern expressway (SE), peacocks highly concentrated along the sides of the road between Pinnanduwa and Godagama. The objective of this study was to find causes, deaths and the methods to conserve peacocks.

This research was based on the qualitative methods. Discussions were made with five expressway officers, four bus drivers, four usual passengers and three local individuals. The direct observation is also included as a data source for the study.

During the construction of the SE from Pinnanduwa to Godagama, quite a number of peacocks newly inhabited on either side of the road and used to walk along and cross the road very often. Unfortunately, peacocks were victimised after the open of the SE to the public from $15^{\text {th }}$ of March 2014. This is because the peacocks are fresh to the vehicles, they usually fly downwards, peacocks cannot run fast but vehicles maintain speed around $100 \mathrm{~km}$ per hour, they cannot react quickly because they are large and also the road is higher than the land surface.

According to the field study, the accident usually happens during the morning hours between $6.00 \mathrm{am}$ to $7.00 \mathrm{am}$ and in the evening around $5.00 \mathrm{pm}$. There are eight buses with damaged front windows because of the colliding with the peacocks. During the first two weeks, the death of peacocks were two to three per day and dramatically down to five to seven per week after two months and the death is continuing from two to five per month at present. However, fencing either sides of the SE up to four to five meters high in the particular area and occasional under road corridors may help to conserve peacocks rather than putting up warning boards for the drivers.
\end{abstract}

Keywords: Peacocks, Southern expressway 